\title{
Diretor da Biblioteca Brasiliana Discute Paradigma entre Preservação e Acesso às Obras do Acervo
}

\author{
Director of The Mindlin Library Discusses Paradigm between \\ Preservation and Access to the Books that Make Part of \\ this Collection
}

Localizada em frente ao prédio de História e Geografia da Faculdade de Filoa Biblioteca Brasiliana abrange um complexo que congrega não só o acervo doado pela família Mindlin à USP, mas também o novo prédio do Instituto de Estudos Brasileiros (IEB) e a sede do Departamento Técnico do Sistema Integrado de Bibliotecas (SIBi-USP), que deverá colaborar ainda para a organização, no mesmo edifício, da Biblioteca de Obras Raras da USP. Além disso, o espaço conta com uma área destinada a exposições e cafeteria, um auditório e as futuras instalações da Livraria João Alexandre Barbosa, da Editora da Universidade de São Paulo (Edusp).

Fruto de investimentos internos e externos à USP, o projeto tem como proposta oferecer ao público o acesso à versão digital dos livros do acervo, o que se tornou possível graças ao desenvolvimento de uma biblioteca virtual, disponível para todos os brasileiros e estrangeiros conectados à internet. Assim, a ideia é que na biblioteca as pessoas tenham contato com tecnologias capazes de ampliar seu contato com o material, tais como iPads e, futuramente, fac-símiles baratos das edições, que serão vendidos na livraria da Edusp. Restritos a objetos de estudo de professores, alunos e visitantes que justifiquem a necessidade de estarem frente a frente com os livros físicos, os exemplares raros da Biblioteca Mindlin estarão disponíveis apenas para consulta no local, em uma sala monitorada por câmeras e com um número limitado de assentos, 24 ao todo.

Órgão da Pró-Reitoria de Cultura e Extensão Universitária (PRCEU-USP), a Biblioteca Guita e José Mindlin guarda preciosidades do acervo reunido por esse grande bibliófilo ao longo de aproximadamente 80 anos, o que prevê um cuidado especial em relação à preservação dos exemplares. Tendo como particularidade o fato de que os livros não circulam - a fim de que sejam conservados -, a biblioteca não tem por objetivo, no entanto, restringir o acesso da população de dentro e fora da universidade a todo esse patrimônio cultural, questão que o atual diretor da Brasiliana, o professor doutor Pedro Puntoni, esclarece em entrevista concedida à Revista Cultura e Extensão USP. 
* "Coleção Brasiliana: livros sobre o Brasil - no todo ou em parte, impressos ou gravados desde o século $X V I$ até o final do século XIX (1900 inclusive), e os livros de autores brasileiros impressos ou gravados no estrangeiro até 1808." (Rubens Borba de Moraes)
Revista Cultura e Extensão USP - A Biblioteca Guita e José Mindlin é considerada uma brasiliana. Quais as características desse gênero de biblioteca?

Pedro Puntoni - Uma brasiliana é um qualificativo, um adjetivo referente a uma coleção, que pode ser de documentos, livros, mapas, gravuras sobre brasileiros ou sobre o Brasil. Uma definição de brasiliana foi dada por Rubens Borba de Moraes *, o que tem muito a ver com a nossa História. Ele escreveu um livro chamado Bibliografia Brasiliana, no qual definiu o que seria esse gênero. Todos os livros escritos sobre o Brasil ou por brasileiros até o ano de 1822 , o ano da independência. Indo um pouco além, são importantes para nós os anos iniciais do século XIX, na verdade, até meados da segunda metade do século XIX, quando a imprensa ainda não está estabelecida no Brasil e os livros, em sua maioria, ainda são raros.

Nós temos que lembrar que a imprensa se implanta no Brasil com a vinda da família real em 1808 e que, a partir daí, começa uma atividade editorial no país, sendo que muitos livros são impressos fora. É um momento de surgimento da história do livro impresso no Brasil. Portanto, quando a gente fala de livros, de uma biblioteca, é plausível imaginar que também livros impressos ao longo do século XIX são livros especiais, raros, valiosos e que devem ser preservados.

RCE - É possível afirmar que a brasiliana doada por Mindlin à Universidade de São Paulo dialoga com a definição formulada por Rubens Borba de Moraes?

P.P. - A coleção brasiliana tem essa definição mais estrita e para nós, no caso, para o professor José Mindlin, tinha uma visão mais ampla. Isso porque ele também tinha livros contemporâneos, mais recentes, de Literatura, História, e a biblioteca dele é uma brasiliana, mas com algumas vertentes.

Como ele construiu uma biblioteca indisciplinada, muito orientada pelo seu gosto de leitura, há algumas lacunas na coleção que são resultantes do fato de ele que não se identificava com determinados autores. Exemplo disso é que nós não temos as primeiras edições de Jorge Amado, porque ele não gostava dele e não se preocupou em comprar seus livros. Mas de Machado de Assis e de José de Alencar, tudo ele tem primeira, segunda edição, Mindlin conseguiu construir isso de uma maneira completa.

RCE - Quais áreas do conhecimento estão contempladas na coleção?

P.P. - As vertentes principais da Biblioteca são: História, Literatura, Sociologia, Arte, viajantes, periódicos brasileiros, primeiros impressos no Brasil, História da Imprensa no Brasil e da Tipografia. Mas não é uma coleção que tem livros de Engenharia? Tem, tem alguns, à medida que eles atingem autores que escreveram os primeiros livros. Medicina? A gente tem uma das primeiras revistas médicas da imprensa, os primeiros tratados sobre doenças tropicais desde o século XVII, não seria só de Humanidades a Biblioteca.

Há também livros recentemente publicados, sempre voltados para essas vertentes. Ele tem Drummond, o que não cabe na definição de brasiliana do Rubens, Guimarães Rosa e autores mais contemporâneos, que davam livros para ele ou que ele comprava.

RCE - É possível mensurar o impacto da doação de Mindlin no que diz respeito aos ganhos para a pesquisa acadêmica na USP? 
P.P. - A Biblioteca é importante porque ela é uma coleção muito valiosa, ela complementa outras coleções que a USP possui, entre elas a do IEB, que é uma brasiliana também magnífica, que data de 1962, quando foi criado o Instituto. Há uma afinidade entre essas coleções, que está manifesta nesse edifício, mas o edifício também se propõe a ser um centro de pesquisa e eu acredito que isso seja algo fundamental.

A Biblioteca guarda uma coleção que tem um valor inestimável e que pretende crescer, ela não é uma coleção morta, parada, um mausoléu. Ela parte do trabalho de 80 anos de um colecionador e tem o compromisso de dar continuidade a essa tarefa, de continuar comprando livros, crescendo, sendo organizada, estruturando essa coleção, para que as pessoas tenham acesso a ela hoje e para que ela seja preservada para o futuro.

Desde o início, o espaço se propõe a ser um centro de pesquisa de estudo sobre o Brasil, a História do Brasil, Sociologia, Literatura, Arte Brasileira e também sobre a História do Livro, da Leitura, das Edições, ela está atraindo colegas que trabalham com isso. É um centro de estudos também sobre a Biblioteconomia, a forma de pensar bibliotecas, a Ciência da Informação e as novas tecnologias em função dela, no caso, a digital. É um lugar onde a gente desenvolveu um laboratório de digitalização ímpar, no qual conseguimos soluções para a digitalização de acervos, que estamos compartilhando com outras entidades no Brasil.

E por fim, é uma biblioteca também voltada para desenvolver um campo novo de conhecimento que é o que tem sido chamado de Humanidades Digitais, como o grupo coordenado pela professora Maria Clara Paixão, da Faculdade de Letras. Ela trabalha com Linguística Computacional e organizou um grupo de pesquisa que tem agregado estudantes de graduação, pós-graduação e professores dedicados a trocar suas experiências em torno do tema.

RCE - Como foi pensado o sistema de digitalização que visa ampliar o acesso ao acervo da biblioteca?

P.P. - Nós nos reunimos com colegas de Engenharia, Comunicação, Matemática, Linguística, Biblioteconomia, para buscar soluções para a digitalização dos acervos, para propor novas formas de acesso usando novas tecnologias. $O$ objetivo é também pensar o próprio papel do digital na humanidade. No fundo, no fundo é trazer sempre um pouco do espírito do José Mindlin. Ele era um homem que colecionava livros antigos, primeiras edições, livros raros, era um homem da cultura, amigo dos escritores, ele mesmo um escritor, um homem aberto, generoso, que abrigava as pessoas na casa dele para consultar os livros e, ao mesmo tempo, um homem da tecnologia.

Mindlin foi um dos fundadores da Metal Leve, foi secretário de tecnologia e quando nós começamos o processo de digitalização, ele foi um dos maiores entusiastas do projeto, o que para ele era um sonho. "Como assim? Quando eu doei a minha biblioteca, eu imaginei torná-la pública, agora é possível tornar o acesso àqueles volumes gratuito e distribuído para todo mundo? Um milhão de pessoas que querem ver aquele livro podem ver?” Podem? Podem, devem. Tem um potencial essa tecnologia, para democratizar o acesso, que é absolutamente extraordinário.

Você digitaliza um livro, um só, por exemplo, a primeira edição do José de Alencar, e o põe on-line. Pode ser que só uma pessoa consulte, pode ser que dez pessoas consultem, 
pode ser que amanhã as escolas de Pernambuco resolvam ver essa edição e, então, um milhão de crianças podem ler o livro. Ou, de repente, cai um trecho da obra no Enem e 200 milhões de pessoas podem falar: "Eu quero ver esse livro", e vão ter acesso ao livro, nada impede.

RCE - Diante de tamanha modernização, de que forma se tem encarado a função do livro físico, guardado em uma biblioteca como a Mindlin?

P.P. - Claro, que a gente gosta de cultivar o papel, o livro, o original, a tipografia, a história do livro, que a gente quer preservar e cultuar, daí, por exemplo, a exposição permanente. A exposição é sobre José, Guita, a formação da biblioteca, mas o foco dela mesmo é a cultura do livro, a tipografia, o livro impresso, a história da imprensa. Assunto sobre o qual as gerações nascidas no digital vêm e perguntam: por que é necessário ter um prédio desses para guardar livros? Por que não colocam tudo em um iPad? Porque não é só o livro digital que importa, ele é uma imagem de um livro que existe no papel e que, provavelmente, vai ser mais duradouro até do que essa nova tecnologia.

Você não sabe quanto tempo isso vai durar, mas o livro a gente sabe, temos exemplares de 500 anos aqui e o digital tem 15 anos, é difícil estimar por quanto tempo vai continuar existindo. Se eles não acharem substituto para o nióbio, ninguém mais vai ter tela multi-touch daqui a dez anos, vai ser necessário inventar uma nova tecnologia que substitua o uso desse metal, que é extraído no Brasil e na China.

Uma das nossas metas é também que, além de ter acesso aos livros, as pessoas possam baixá-los e imprimi-los. Havia até um projeto que a gente estava construindo com o antigo MinC (Ministério da Cultura), para poder comprar uma espresso book machine, o que, na verdade, é uma impressora encadernadora, que atualmente várias gráficas têm. A ideia de ter esse equipamento seria interessante, para podermos criar coleções de fac-símiles baratos dos nossos livros e disponibilizá-los na livraria da Edusp. Assim você tem o livro em mãos para ler.

RCE - Qual o diferencial da Brasiliana em relação às demais bibliotecas da USP?

P.P. - Assim como o IEB, a Biblioteca Mindlin tem uma dupla dimensão muito clara. É uma biblioteca para ser trabalhada hoje, mas é uma biblioteca para preservar esses bens culturais para as gerações futuras.

É diferente da biblioteca da Faculdade de Filosofia, que é uma biblioteca de pesquisa, de consulta, didática. $\mathrm{O}$ objetivo dela é atender o público acadêmico que frequenta aquela escola, ela é usada, aliás, até um pouco mal usada. Os livros estão destruídos, consumidos, jogados nas mochilas, mas é assim que é aquela biblioteca, a nossa não. Por isso que o livro não circula, ele precisa ser preservado, para que vocês leiam os livros, os netos de vocês leiam os livros e os tataranetos de vocês leiam, é importante que aquele mesmo livro esteja ali. A mesma edição vai estar preservada, porque, vejam bem, a primeira edição de José de Alencar, por exemplo, tem dois exemplares no mundo, um na Biblioteca Nacional e outro aqui. Foi um dos livros mais vendidos no século XIX e quase todos se perderam, sobraram dois. Por quê? Era um livro barato, as pessoas jogavam fora, temos que preservar isso, então, essas duas dimensões: preservação e acesso. 
RCE - Como foi feita a seleção dos grupos de pesquisa que ocupam lugares no interior da Biblioteca? Quais são os principais assuntos a que eles se dedicam?

P.P. - Na verdade, os grupos que estão instalados na Biblioteca são os grupos que têm trabalhado com a gente nos últimos anos, mas estamos abertos a pensar em outros, a biblioteca precisa se institucionalizar melhor. Até agora ela tem um diretor interino, que sou eu, e vai ter que instituir um Conselho, que precisa ser regulamentado.

Entre os grupos de pesquisa que trabalham na Biblioteca, está o Núcleo de Estudos do Livro e da Edição, que é coordenado pelo professor Plínio Martins, presidente da Edusp, e pela professora Marisa Midore - responsáveis pelo seminário dos 50 anos da Edusp. Então, claro, tem tudo a ver com a Biblioteca, tem que vir pra cá. Eu gostaria de um dia deixar de ser o burocrata que sou, o administrador, e trazer o meu projeto de estudos de História do Brasil para cá, mas seria bom ter um grupo de História aqui. De Humanidades Digitais, já tem um ano que eles estão aí, fizeram um blog, estão organizando simpósios, workshops. Sem falar no laboratório de digitalização da Brasiliana, que tem atuado cada vez mais como um núcleo de pesquisa, desenvolvendo projetos com o apoio da FAPESP, da Petrobras, do BNDES. Eles têm mandado gente para congressos, publicado alguns textos, trazido alunos de pós-graduação, então é esse o objetivo. De Literatura, agora nós temos um grupo de professores de Literatura Comparada que está propondo um projeto para montar aqui.

A gente quer estar aberto a esse tipo de iniciativa, por isso, precisamos criar um Conselho Acadêmico. Hoje a gente tem só um grupo de professores colaboradores mais próximos, que são quatro e tem estado aqui quase todos os dias, e temos um grupo de professores que colaboram esporadicamente, vêm em um seminário, contribuem com a digitalização, mas é algo a ser estruturado.

RCE - Como funciona o processo de digitalização? Seria possível descrever o trato cuidadoso a que as obras são submetidas para que possam ser disponibilizadas digitalmente?

P.P. - A digitalização é o processo de transformação de um livro físico, que está impresso no papel, em uma versão digital. Há várias formas de se fazer isso, uma delas seria pegar o livro e digitá-lo. Assim teríamos o texto do livro impresso, mas esse não é o modelo pelo qual nós optamos. A nossa digitalização é feita em referência ao objeto original. Quando a gente digitaliza a primeira edição do Memórias Póstumas de Brás Cubas, por exemplo, queremos que as pessoas vejam como é a diagramação, a tipografia e isso leva à escolha de algumas tecnologias como, por exemplo, o scanner robotizado que adotamos em 2009.

Compramos outros modelos mais recentes agora, porque eles permitem a digitalização de livros encadernados sem afetar a sua estrutura. O livro é posto em uma espécie de berço e vai sendo folheado para que as imagens sejam capturadas com câmeras fotográficas e não com scanners de varredura. É uma opção tecnológica para o resultado que a gente quer obter, preservando o original. No caso do scanner de varredura, na maioria das vezes, você tem que pressionar livro sobre o vidro, ou o vidro sobre o livro, para que ele funcione e é certo que a nossa curadora não ia permitir fazer isso com nenhum exemplar da biblioteca. 
**"Em relação aos livros, não tenho o fetiche da propriedade. Sinto-me mais como um depositário do que um proprietário, usufruindo, é verdade, do prazer que eles proporcionam, mas visando sempre preservar uma herança do passado, e conservar o que se faz de bom agora, com o propósito de transmitir tudo isso para o futuro. Tenho procurado desenvolver uma atividade cultural em várias frentes, facilitar a estudiosos a pesquisa na biblioteca, promover edições de obras úteis e reedição de outras esgotadas que considero importantes. Desenvolver, em suma, um trabalho que é uma das minhas razões de ser na vida." (José Mindlin)
Depois de terem a foto de suas páginas capturadas, os livros são digitalizados, isto é, as imagens são processadas, tratadas, limpas, transformadas em preto e branco e geram um ".pdf". Este ".pdf”, por fim, passa por um software de reconhecimento óptico de caracteres, o OCR (Optical Character Recognition), a fim de que o documento se torne "buscável", ou seja, que por trás das imagens do livro, tenha um texto digitado, digital, do livro, com maior ou menor acerto, dependendo da época em que o material foi escrito. Então é isso, a qualidade da impressão é o que define o bom ou o mau resultado do software de OCR.

Após a realização dessas etapas, o ".pdf” é colocado on-line em um repositório digital, nossa plataforma de acesso, sendo que para que isso aconteça, todo o processo necessita de uma estruturação da coleção, um descritivo, que a gente chama de metadados, uma ficha do livro. As imagens originais fotografadas são guardadas em um back-up para serem usadas de novo ou reprocessadas se preciso, como no caso de alguém necessitar de uma edição em alta resolução.

Assim, sempre que houver uma demanda dessas imagens, para não termos que refotografar o livro, podemos recorrer ao que foi guardado: a imagem original, a imagem tratada, o ".pdf” final e o output, que é colocado on-line.

RCE - Considerando a história de vida de José Mindlin, que ensinamento fica para aqueles que poderão usufruir de parte do seu legado dedicado aos livros do acervo?

P.P. - José Mindlin** sabia que a coleção que havia construído ao longo de 80 anos escapava à propriedade de uma pessoa, de uma família e que tinha se tornado, necessariamente, uma coleção que deveria ser pública. Chegou uma hora que não tinha mais sentido que os livros ficassem nas mãos de uns poucos, porque eles deveriam ser de todos. Isso produziu esse gesto original, generoso deles, não só do José, mas da mulher dele, da Guita, e dos quatro filhos, que também abriram mão de uma herança extraordinária em prol da doação para a USP.

Mas não para doar para a USP porque ele gostava da USP, sim, ele gostava - porque todos os filhos dele estudaram aqui, porque ele estudou aqui, quando ainda existia só a Faculdade de Direito, porque ele conheceu a esposa aqui e viu a USP ser criada -, mas porque, ele achava que a USP teria condições de abrigar a biblioteca em plenas condições de conservá-la para o futuro e garantir o acesso a todos. Sempre essa dupla dimensão: preservação e acesso é o norte que tem nos orientado e é o que os visitantes precisam ter em mente para usufruir melhor do acervo.

RCE - O que a comunidade acadêmica pode esperar das atividades da Biblioteca, como a exposição "Uma Vida entre Livros"?

P.P. - A exposição "Uma Vida Entre Livros” será permanente, ou seja, de longa duração, sendo seus principais temas: a formação da biblioteca, a vida de José e Guita, a cultura do livro, a História da Imprensa no Brasil e o prazer pela leitura. Assim, esperamos que atraia pessoas de fora da USP, já que ela também é voltada para o grande público. De uma forma mais agradável e ampla, a exposição visa atingir não só pesquisadores, mas pessoas em geral, para introduzi-las nessas dimensões da história da biblioteca, da vida do José, da cultura do livro e do prazer da leitura. 
Além disso, outra exposição, que é conexa a essa, mas que vai ser apresentada por menos tempo, sendo de curta duração, trata dos “Destaques da Biblioteca Mindlin”. Elas trabalham juntas, é o mesmo projeto, mas essa vai ficar exposta somente durante os três primeiros meses após a inauguração do prédio. Isso por conta da questão que envolve a conservação do material exposto que, como o próprio o nome diz, é composto dos destaques da Biblioteca Mindlin. Por fim, a ideia é que haja na Biblioteca um conjunto de atividades culturais ligadas ao auditório, um espaço de cinema, música, conferências, palestras, eventos e exposições.

RCE - Para concluir, qual a importância das pessoas terem acesso aos livros físicos, mesmo que esse acesso seja restrito?

P.P. - Existem lugares na USP que são assim, você vai procurar um livro e: "Ah não, esse livro você não pode ver". Limitam, impedem o acesso. É uma tendência de alguns acervos, que olham para a preservação e para o acesso e concluem: "São coisas antagônicas”. Claro que folhear o livro pode ajudar a destruí-lo, mas ter conhecimento e contato com a informação é também a única forma de garantir que ela seja preservada. Porque também, se você fechar essa coleção toda dentro de um baú de aço a vácuo e jogar no espaço significa que ela se perdeu.

Se você trancar um arquivo e não deixar ninguém vê-lo, a tendência é que ele se deteriore. E mesmo que só um bibliotecário tenha acesso, quem disse que ele está garantindo a preservação sozinho? O pesquisador é um dos maiores aliados da preservação, porque ele vai lá e pergunta: “Cadê o documento, como assim 'ele se perdeu'?" É isso que acontece e geralmente a visão custodial mascara a destruição dos nossos acervos.

Por isso, aqui na Brasiliana nós temos negado isso e mostrado que, por exemplo, a tecnologia do digital permite conciliar esses polos aparentemente antagônicos, garantindo o acesso pleno à informação e preservando o livro da manipulação. Tudo isso sem deixar de dizer para todo mundo que nós temos aqueles livros, eles estão aqui. $\mathrm{E}$ você vai poder, daqui dez anos, questionar: "Eu estou vendo uma imagem da primeira edição do José de Alencar. Deixa eu ver o livro. Ué, mas estão faltando páginas. O que aconteceu, se eu tenho uma cópia dele aqui?" Dando acesso à coleção você garante que ela seja melhor preservada, para que outras gerações conheçam também a importância desse patrimônio.

PEDRO PUNTONI professor doutor do Departamento de História da Faculdade de Filosofia, Letras e Ciências Humanas da Universidade de São Paulo (FFLCH-USP), diretor da Biblioteca Brasiliana Guita e José Mindlin da USP e coordenador do Projeto Brasiliana USP - e-mail: puntoni@usp.br

MARINA SALLES graduanda do curso de Jornalismo da Escola de Comunicações e Artes da Universidade de São Paulo (ECA-USP) e bolsista da Revista Cultura e Extensão USP - e-mail: marina. salles.jor@gmail.com 
Figura 1 - No dia 23 de março de 2013, foi inaugurada a nova sede da Biblioteca Mindlin no campus da Cidade Universitária. Trata-se de um moderno edifício, projetado pelos arquitetos Eduardo de Almeida e Rodrigo Mindlin Loeb, e que utiliza as mais avançadas tecnologias de preservação e segurança. São cerca de 6.900 m2, nos quais todas as necessidades para a alocação dos livros e documentos da coleção José e Guita Mindlin são integralmente atendidas. Foto: Ricardo Amado.
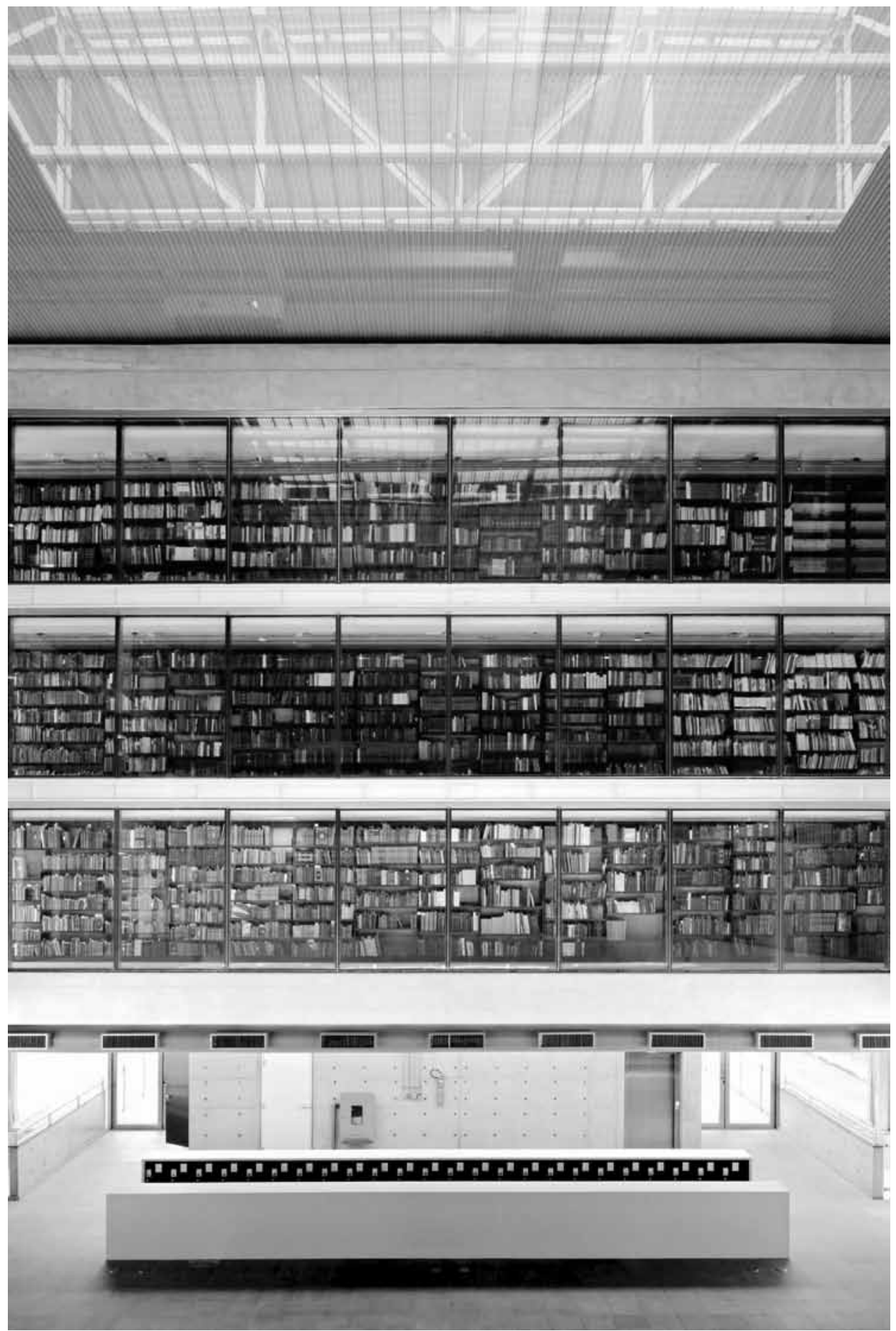